\title{
Critical Social Pedagogy in Mathematics Teacher Education
}

\author{
Olawale, B. E. ${ }^{1}$, Mncube, V. S. ${ }^{1} \&$ Harber, C. ${ }^{1}$ \\ ${ }^{1}$ Faculty of Education, University of Fort Hare, South Africa \\ Correspondence: Olawale, B. E., Faculty of Education, University of Fort Hare, South Africa.
}

Received: April 5, 2021

Accepted: June 14, 2021

Online Published: June 16, 2021

doi:10.5430/ijhe.v10n6p93

URL: https://doi.org/10.5430/ijhe.v10n6p93

\begin{abstract}
There is no how-to recipe for implementing pedagogical approaches, as each school, learner and teacher has a unique perception of the nature of critical mathematics education. It is therefore the duty of educators and school administrators to cultivate critical teaching and learning experiences that can connect the standardised school curriculum to the reality of learners' everyday lives. As such, this study investigated the pedagogical approaches which mathematics teacher educators employed in the development of democratic citizens in South African universities. Underpinned by the constructivist paradigm, the study employed a qualitative research approach and a case study design. Data were generated from a total of six mathematics teacher educators and 75 second- to fourth-year student teachers majoring in mathematics education across three different universities. The findings from the study revealed that there are contradictions between pedagogical philosophies and the mathematics teacher educators' ideal image of their practice in the classroom. The nature of mathematics teaching, and the fear that learners come to class with different knowledges from their personal experience and have disparate opinions, hinder critical and social engagement within mathematics education classrooms. Based on the findings, it is recommended that mathematics teacher educators employ a problem-posing pedagogical approach which allows for the appropriation of knowledge in the form of self-reflection, a synergy of care, and self-determination which seeks to foster democratic values and critical consciousness in the development of democratic citizens.
\end{abstract}

Keywords: curriculum, democracy, democratic citizens, education, pedagogy

\section{Introduction}

Approaches to mathematics teaching that do not question the curriculum and/or injustices in society, hold severe limitations for learners. This is because good teaching alone does not necessarily help learners to overcome the inequities which stem from racism, classism and sexism in society (Harper, 2018). Thus, learners need a critical awareness of how to advocate for themselves, for their own mathematics learning and for more equitable opportunities. Research has, however, shown that promoting social fairness and justice (in mathematics education, in particular) can help to support democracy, increase political participation amongst young people, improve their political knowledge, and promote tolerance and social cohesion for democratic citizenship (Ellis \& Malloy, 2007; Trent et al., 2010; Wonnacott, 2011). As Skovsmose (2011) asserts, teaching mathematics for social justice creates a challenge in that it may achieve the opposite, namely to disengage and incapacitate learners. This article draws on the notion of "critical education", as advanced by Freire (1968), which advocates for the liberation of learners and the development of critical citizenship. Based on this concept, mathematics education is expected to play a vital role in addressing societal challenges, such as unstable economic growth, human rights abuses, and persistent or growing inequality (Cotton, 2013). Worryingly, some learners reject mathematics (or feel rejected by mathematics!) for various reasons, including classroom practices that are inherently undemocratic, teachers' (or societal) perceptions of their ability, a neglect of traditional/cultural approaches to teaching and learning, or the low expectations of their teachers, parents and society (Ellis \& Malloy, 2007). As a result, many fail to see the importance of doing mathematics, and are not capacitated as users of mathematics (Ellis \& Malloy, 2007). To empower learners to become users of mathematics, researchers have proposed possible ways in which mathematics learners can be assisted to develop the requisite content knowledge. This stems from the belief that such knowledge is capable of developing and promoting learners' abilities to critique injustices in their immediate society, with the assumption that such practices would be capable of bringing about academic and social transformation (Gutstein \& Peterson, 2005; Ellis \& Malloy, 2007; Turner \& Font-Strawhun, 2007; Stemhagen \& Smith, 2008; Wright, 2016). The present study therefore seeks to examine the pedagogical approaches employed in mathematics teacher education programmes, in terms of developing democratic citizens. 


\section{Literature Search: Critical and Social Pedagogy in the Mathematics Classroom}

\subsection{Critical Pedagogy and Mathematics Education}

Many believe mathematics is not important, because it is presented and practised in the same way all over the world. Similarly, many believe mathematics has no significance, and make this statement in an apolitical way (Aslan-Tutak et al., 2011). However, Groth (2006) gives an example that disrupts ingrained assumptions about the role of mathematics, using two definitions of a trapezoid. The first explains a trapezoid as a quadrilateral with exactly one pair of parallel sides, while the second states that a trapezoid is a quadrilateral with at least one pair of parallel sides. The two illustrations presented here are accepted both in mathematics and mathematics education (Groth, 2006; Aslan-Tutak et al., 2011). From a more critical perspective, however, these definitions reveal contradictions. According to Aslan-Tutak et al. (2011), the first illustration is very restrictive, while the second creates an opportunity for more quadrilaterals to be characterised as trapezoids. For instance, going by the second illustration of a trapezoid, a rectangle can thus be classified as a trapezoid (but not according to the first definition). Aslan-Tutak et al. (2011) state that this mathematical problem (and many more) is not value-free, but carries hidden messages, as does the practice of other basic operations. Critical theorists admit that this reasoning about mathematics and its teaching holds water, but emphasise using pedagogical approaches in the classroom that are capable of assisting learners to use mathematics to reach their immediate society (Groth, 2006; Aslan-Tutak et al., 2011). In some ways, all classroom discourse is critical because it is inherently political, and at the heart of critical pedagogy is an implicit understanding that power is negotiated daily by both teachers and learners (Sarroub \& Quadros, 2015). For Sarroub and Quadros (2015), the classroom is a unique discursive space, suited for enacting critical pedagogy.

According to Lilia (2004), critical pedagogy is mainly concerned with educational practices and theories that foster our understanding of the relationships between ideology, culture and power structures. Hence, critical theory has evolved to become "a crucial body of scholarship in education that offers a lens for understanding the role of schools in propagating and challenging [the] race, class and gender interests of state and society" (Jansen, 2009, p. 150). Aslan-Tutak et al. (2011) posit that the goal of critical mathematics education should be to empower learners with suitable knowledge, skills and dispositions for creating democratic communities, by embracing social justice in and outside of school. For Gutstein (2006), the main objectives of critical pedagogy in mathematics education include reading mathematical worlds, succeeding academically (in the traditional sense) and changing learners' (and teachers') orientation to mathematics. As Gutstein (2006) continues, reading the world implies developing mathematical powers which encompass the ability to deduce mathematical generalisations and construct creative solutions to a problem, while perceiving mathematics as a tool for socio-political criticism. Academic success in the real sense implies that learners must excel by passing tests and examinations, and graduating from school in pursuit of careers related to mathematics. Changing people's orientations towards, and perceptions of, mathematics implies understanding mathematics not as a series of incoherent rules to be memorised, but as a powerful tool for grasping complex, real-world phenomena (Gutstein, 2006). As Bartolomé (1996, p. 249) adds, "unless educational methods are situated in the learners' cultural experiences, they will continue to show difficulty in mastering content $[\ldots]$ that is not only alien to their reality but is often antagonistic toward their culture and lived experiences". Thus, Aslan-Tutak et al. (2011) argue that critical pedagogy in mathematics education does not lessen the excellent achievements of learners, but rather seeks to educate citizens for a more just and democratic society.

\subsection{Social Pedagogy and Education}

Social pedagogy is a relationship-based approach which aims to combine academic knowledge with an understanding of emotions, in the context of hands-on practical work, to arrive at "a holistic humanistic approach" (Lloyd et al., 2014). It encourages non-traditional teaching approaches and creative experimental tasks. According to Eichsteller and Holthoff (2012), the humanistic nature of social pedagogy can be encapsulated in the expression "head, heart, hands" - a phrase first coined in the late 18th century by Johann Heinrich Pestalozzi, a Swiss educational reformer, to demonstrate that the whole person is involved in the process of teaching (Black et al., 2017). For Pestalozzi, the essence of teaching is to be found in the connections between the aforementioned three elements (Soertard, 1994). From a social pedagogical standpoint, a synergy of care and education in the classroom can be established and maintained by "being" with children as opposed to "doing". Thus, Cameron et al. (2011) posit that the main focus of social pedagogy is the child as a whole. It recognises that learners form part of a complex society, that they think and feel, and have a physical, social, spiritual and creative existence, all of which continually interact. Social theorists encourage educators who wish to employ social pedagogy to bring themselves fully to their classrooms, by constantly reflecting on their practices as they work to help their learners overcome the challenges 
confronting them (Petrie et al., 2009). Such educators are encouraged to draw on successful confrontations, and to apply the theoretical underpinnings thereof to their everyday practice (Petrie et al., 2009).

\section{Theoretical Underpinnings}

This study draws on the political democratisation theory - a liberation theory put forward by Paulo Freire (1968), a prominent educationist in Brazil. This theory proposes an unpretentious education for democracy, where an effort is made to engage in fair discourse, investigate a chain of evidence and thinking, and raise critical awareness of political practices. The purpose of this kind of education is to assist learners in forming opinions for themselves either politically or socially - on the basis of choices that are well versed, rather than exercised due to (forceful) indoctrination (Harber, 1997). Freire (1968) encourages teaching for critical consciousness, to develop critical thinking and awareness so that learners become active and creative agents who are capable of reconstructing and changing society. The key constituents of Freire's (1968) liberation theory are freedom, critical participation and democracy. Thus, he discards the educator-learner binary and suggests that a profound commonality be introduced into the thinking of every learner-educator and educator-learner relationship (Freire, 1968). Notably, Harber (2009) argues that, with schooling, there is conflict between the type of education that strives to produce people who are obedient and politically passive, and an education that urges people to be critically aware, seek freedom and participate in democracy. Harber (2009) affirms that, while the latter approach to education has been prevalent among some educational experts and policy makers, globally the main drive of schools, for power and conformity, is intensely embedded in the prevailing, dictatorial ideal of schooling - something which is very difficult to change. In addition, Harber (2009) argues that, around the world, the predominant education systems adhere to an authoritarian mode of teaching and learning, where learners have little or no room to voice their opinions when or how they want to. Thus, the implication of this theory, for the current study, is that universities and educational institutions which are mandated to educate teachers, are currently guided by their obligation to provide the expertise, knowledge and qualifications needed to sustain the work environment (Giroux, 2006). Subsequently, little attention is paid to understanding and/or appreciating the pedagogical foundations of higher education institutions (HEIs) as arenas of political, critical and social practice - in other words, pedagogy as a practice and process of freedom. This is because, as schools strive to conform to business's obligation of producing graduates for the workforce, any visible traces of a critical education are quickly substituted for training and the affirmation of economic certainty (Giroux, 2010). That is why the idea of a democratisation theory suggests that schools should first strengthen learners' voices and their involvement in the process of making decisions in the classroom (Agyemang, 2012). This is because schools and communities both grant and limit learners' learning opportunities and their commitment to democracy.

\section{Problem Statement and Research Question}

Teacher education has been viewed as a one-way approach which puts the teacher in control of the instructional process. That means learners become passive recepticles of knowledge, who are expected to be quiet, listen and learn whatever is being taught to them (Darling-Hammond, 2010). In the words of Freire (in Patel, 2010), the teacher-learner relationship is poor simply because many teachers merely narrate details about their subject, while the learners listen without really becoming involved. In his 1968 essay, "The banking concept of education", Freire explains the three main elements of learners' activities in the classrooms as being memorising, receiving and repeating information. During this kind of teaching and learning practice, teachers avoid dialogue because they do not want to have any interaction/conversation with their learners (Patel, 2010). Freire $(1968,1970)$ argues that such educators use their learners to make themselves "good teachers", thereby continuing to oppress their charges. For such educators, teaching remains a goodwill-oriented, symbiotic experience. Those teachers desire that learners perform better and obtain good grades, and little else. Indeed, many educators do not care what happens in their classrooms, and some are not even aware that they are teaching according to the "banking" concept, which dehumanises learners (Patel, 2010). They also do not realise that certain "deposits" clash with reality, and for that reason there is a need to follow a pragmatic approach to developing and educating teachers on modern and contemporary teaching styles (Patel, 2010). As such, a gap thus exists to scrutinise teacher preparation programmes in order to ascertain whether the ideals of democracy are advanced within the classroom parameters, so that when stepping out for classroom practice, teachers can become democratically "contagious" in both their practices and their pedagogical approaches. Thus, in order to examine these pedagogical approaches, as employed by mathematics teacher educators in the development of democratic citizens, the following research questions were raised:

i. How do mathematics teacher educators and student teachers of mathematics engage in critical and social pedagogy? 
ii. Why do mathematics teacher educators and student teachers of mathematics engage in critical and social pedagogy in the manner they do?

\section{Research Methods}

Underpinned by the constructivist paradigm, the study employed a qualitative research approach - one which Ormston et al. (2014) define as naturalistic and interpretative, and concerned with investigating phenomena from an inner perspective, working from the viewpoints and accounts of the research participants. The qualitative approach was employed to gain a clearer perspective of the pedagogical approaches which mathematics teacher educators employ in developing democratic citizens. A case study research design was also used. As Yin (2013) affirms, case studies are the most appropriate strategy to employ when contextual conditions are relevant to the phenomenon under study. Using a multiple case study design assisted the researchers in selecting research sites and participants from various backgrounds, with a variety of experiences in respect of how they were prepared, and the pedagogical approaches employed to develop democratic citizens. The researchers purposively selected three traditional universities (which provide theoretically oriented university degree programmes) in South Africa, with the expectation that they would report unique and interesting data with regard to democratic citizenship and the preparation of mathematics teachers. In the end, the targeted population for the study consisted of mathematics teacher educators and mathematics student teachers from all three universities. That included the lecturers of would-be teachers, and students who were preparing to become mathematics teachers once they had obtained a Bachelor of Education (BEd) degree. At each of the three universities, the sample comprised two mathematics teacher educators and 25 preservice mathematics student teachers in their second to fourth years of study. Thus, the sample consisted a total of six mathematics teacher educators and 75 preservice mathematics student teachers. Purposive sampling was used to identify teacher educators charged with the responsibility of training mathematics student teachers at the selected universities. Next, it was employed to identify 25 second- to fourth-year student teachers majoring in mathematics education, who were undergoing teacher training. The selection was based on the fact that the selected samples would be ideally suited to provide information on their lived experiences in the course of the programme. As such, data were gathered through semi-structured interviews with mathematics teacher educators and mathematics student teachers, and by means of observation and document review (such as lesson notes, lesson plans, as well as the institutional teaching and learning policies). Thus, data trustworthiness was ascertained through the triangulation of data sources. For ethical purposes, confidentiality, anonymity and privacy were respected with the exception of information that alluded to harm being done to an individual. This proviso was communicated and agreed to before the start of data collection; and consent of all participants was sought.

\section{Data Analysis}

This study employed a thematic data-analysis procedure, as proposed by Braun and Clarke (2006), which comprises six steps: gathering data; generating categories, themes and patterns; coding data; testing emergent understanding; searching for alternative explanation(s); and report writing. For the purpose of data presentation, the three HEIs visited for this study were differentiated through the use of fictitious names such as University X, University Y and University Z. The data collected from the interviews are presented in relation to the interview questions and raw responses received from the participants affiliated with those universities. This was done to arrive at a holistic view of the participants' responses. Two mathematics teacher educators each from University $\mathrm{X}, \mathrm{Y}$ and $\mathrm{Z}$ were coded as ME1 \& 2 at University X, Y or Z respectively, and the mathematics student teachers were coded as ST1-25; followed by University $\mathrm{X}, \mathrm{Y}$ or $\mathrm{Z}$.

\section{Results and Discussion}

The study sought to examine which pedagogical approaches are employed by mathematics teacher educators in the development of democratic citizens. To this end, the results and discussions are presented under the following themes:

- Engagement in critical and social pedagogy in the mathematics education classroom

- Reasons for engaging in critical and social pedagogy in the mathematics education classroom

\subsection{Engagement in Critical and Social Pedagogy in the Mathematics Education Classroom}

Mathematics student teachers were asked: "How do you engage with your mathematics educators in critical and social pedagogy?" In turn, the mathematics teacher educators were asked: "How do you engage with your mathematics student teachers in critical and social pedagogy?" The research findings revealed that the participants had varying perspectives with regard to their engagement in critical and social pedagogy in the classroom. While the majority believed no engagement took place in terms of critical and social discourse in the classroom, a few held the 
opposing view. Some stated that raising broad-minded ideals (such as the fight against racial discrimination, sexism and gender disparities) are ways in which the morals of social justice can be instilled, by engaging in critical and social pedagogy in the classroom. As one participant stated:

We engage in critical and social discussion through [an] illustration of events happening in the society, then [...] questions are posed to stimulate and encourage students to respond. For example, in class we were debating about a teacher dating a 16-year-old learner in his school; students wanted to know if it is right or wrong. Then a colleague answered and said, 'Yes, because democracy allows us to do whatever we like, we live in a free world with freedom and freedom of expression. Therefore, if the feelings between them are mutual, there is no problem.' Then I got up to say, 'No, because as teachers, you must be professional,' so the debate at times [was] heated and got out of hand. That, most lecturers find [...] difficult to handle.... So, we do engage. (ST2; University Z)

At University Y, a mathematics educator who believed that he engaged with his students in critical and social discourse, explained:

How? Through [a] collaborative and cooperative learning environment where the defenseless can use strength in numbers to challenge the powerful. I also create a space for engagement in which students can identify unethical power dynamics and [I] encourage them to fight for the powerless. For example, by examining the history of apartheid through [a] critical lens within [the] mathematics education classroom, students are made to understand how apartheid policies predestined the black majority to slavery and dehumanisation - although we really do not apply mathematics, but students are encouraged to discuss [these] issues so that they are able to identify injustice in their immediate society. (ME2; University Y)

These findings suggest that mathematics educators and student teachers in fact engage in social and critical discourse in the classroom, using collaborative and cooperative strategies which enable the students to see mathematics as a tool for confronting issues of justice within society, and for showing their commitment to democratic principles. This finding corroborates the view of Sarroub and Quadros (2015), who state that in utilising critical pedagogy, teachers should employ strategies that promote high-quality questions relating to various stages of Bloom's (1956) taxonomy. This is because these strategies encourage higher-order thinking skills within the cognitive domain, and help learners, teachers and educators alike to cultivate an understanding of how ideology, power and culture interconnect (Lilia, 2004). McKinney et al. (2004) and Forbes and Kaufman (2008) state that although cooperative, collaborative and problem-based learning are movements away from the traditional method of teaching to a more learner-centred approach, they also constitute an integral part of a critical pedagogy which is capable of liberating learners. As Bartolomé (1996) argues, critical pedagogy is a humanising pedagogy that accepts and values learners' and teachers' contextual knowledge, culture and lived experiences. It is therefore not a one-size-fits-all pedagogical approach (Bartolomé, 1996), because it moves both learners and teachers to a personal, ever-expanding understanding of their existing world(s) (Greene, 1996). Thus, critical pedagogy embraces a problem-posing pedagogy, while social pedagogy supports a complete, humanistic approach which establishes a spirit of creative, experimental tasks through a non-traditional teaching approach (Lloyd et al., 2014).

The researchers also found that mathematics student teachers who claimed to engage in critical and social discourse through debates with their educators, still feared what those educators might say, and that prevented them from entering into discussions capable of creating a space for understanding the relations of power and privilege that manipulate and distort social relationships. As one participant explained:

We always engage with our lecturers in debates relating to different issues happening on campus - say, for instance, foreign national discrimination, GBV [gender-based violence] and rape cases or any other issue outside mathematics method class, but not [as] deeply as we would have loved to. Because, what if we do and it opposes the lecturer's view, [s/he] might feel that we are underestimating [his/her] abilities or trying to take over [his/her] teaching periods with irrelevant discussions and [s/he might] decide[ ] to shut us up. (ST12; University Z)

This finding does not seem to indicate that the teaching and learning space created for enagement in critical and social discourse goes beyond critical thinking ability - it does not obviate the fear of penalties. Giroux (2010) states that engagement in social and critical pedagogy should offer students an opportunity to develop the ability to think critically. This is because that ability goes beyond the fear of consequences, and prepares students for the obligations they have in terms of social responsibility (Giroux, 2010). This is why Sarroub and Quadros (2015) suggest that teachers must question their own classroom practices in the process of knowledge construction, in order to use social and critical pedagogy effectively. Aslan-Tutak et al. (2011) posit that critical educators are devoted to the democratic 
principles of justice and fairness, and are also concerned about educating their learners to examine the state of affairs around social justice in their world, from a critical perspective. Thus, critical theory in education is about emancipating, illuminating and empowering learners as well as student teachers (Aslan-Tutak et al., 2011). Although there are variances between educational experts and scholars who have shaped the meaning of critical pedagogy, there are essential commonalities which include social and educational justice and equality (Aslan-Tutak et al., 2011). A common understanding of critical pedagogy recognises that critical teachers must challenge their own individual ways of knowing (as well as those of their learners), which are deeply rooted in conventional ways of reasoning that often limit their potential (Kincheloe, 2004; McLaren, 2009). This kind of critical thinking will lead to critical awareness which enables learners to appreciate their lives in new ways, and to consider various means of revolutionising those structures that consistently oppress people (Aslan-Tutak et al., 2011).

During observation, the researchers noted that the student-educator relationship is capable of promoting critical and social discourse in the classroom, but that it is poor as a result of the physical setup of chairs, tables and the classroom layout. In particular, the layout makes it impossible for both student teachers and educators to engage in meaningful interaction that would allow the former to learn effectively, or challenge existing power structures. This physical arrangement has the potential to encourage desirable behaviour as well as misbehaviour in the classroom. Similarly, it encourages and discourages involvement in debates and learning processes. During teaching and learning, the educators assumed a position of authority, standing in front of the classroom while they employed a lecture-based approach as the all-knowing lecturer charitably sharing knowledge with the humble students. In the classroom, questioning either the educators or the societal status quo - which could empower students to become aware of themselves - was not encouraged. Instead, the educators used their knowledge to encourage students to arrive at the "correct" final answers, rather than urging them to interrogate and challenge imbalances at the institution, in their methodology courses, in their families and in their immediate society. Arguably, if critical and social pedagogy are all about challenging power structures and understanding emotions in the context of practical work, one of the greatest power dynamics in a student's life is the student teacher-educator relationship, or later the relationship a teacher has with his/her learners.

Upon reviewing the mathematics educators' learning guides, it was evident that those who claimed to engage students in critical and social discourse employed a traditional teaching and assessment structure, which focused on providing students with facts/model answers. Traditional teaching and assessment constructions which focus on final answers, or compel students to do what they need to do to obtain a particular grade to succeed, restrain students from thinking critically. As Fang (2012) posits, critical pedagogy is not standardised, nor does it have a fixed text regulation (standard assessment criteria/procedure), well-established teaching techniques or implement centrally controlled examinations, because its approach varies considerably from one class and subject to another.

The researchers' findings, obtained from the interviews with the participants on how they engage in critical and social discourse in the mathematics education classroom, refute the findings from both the observation and the document review. Arguably, mathematics teacher education classrooms do not promote engagement in social and critical pedagogy, as is evident from student teachers' inability to exchange their opinions, due to the traditional setup of classrooms - the layout negatively affects the student teacher-educator relationship, thereby forcing the latter to employ authoritarian pedagogical approaches. This finding corroborates the view of Franzosi (2006), who states that one of the most problematic and impossible tasks facing the critical instructor is having to break down the student-educator incongruity and having to re-socialise students to accept critical learning experiences. This is because many are more content with the old-fashioned model of classroom structure, which emphasises the compulsion of note taking and the regurgitation of information (Forbes \& Kaufman, 2008). As Franzosi (2006) states, although educators have some degree of established and academic authority, they can still adapt the classroom to create a space which encourages students to both share and, where applicable, negate authority.

Bickel (2006) suggests that teachers should consider "democratising the classroom", so that learners can decide on the topics to be covered, the seating arrangements in the venue, the amount of reading allocated per week, the number of pages and submission dates for lengthy assignments, and attendance policies. All these agreements will only be possible through the active participation of learners in the decision-making process that occurs within the classroom, in the form of debates and dialogues (Bickel, 2006). As Bickel (2006) argues, when teachers welcome learners to take co-ownership of the classroom, they might end up earning greater respect and, unexpectedly, more power, while building good relations with their learners. This will assist teachers in eradicating the contradiction between learners and teachers in a power relationship. For Freire (1998, p. 81), eliminating these contradictions does not mean that a teacher has stopped teaching; rather, it suggests that "both the educator and the students recognize that open and curious questioning, either through discourse or listening, is what mutually binds them". 
The researchers noticed that the traditional grading and assessment culture, which is geared towards a step-by-step evaluation process that students embark on as they seek to obtain the right answers, shapes how mathematics student teachers and educators engage in critical and social pedagogy. This finding corroborates the views of Forbes and Kaufman (2008), who state that one of the major challenges hindering critical pedagogy in the classroom is a method of assessment which is complicated, yet different from the traditional grading and assessment technique. Forbes and Kaufman (2008) argue that if the aims of critical pedagogy are to stimulate discourse and inspire students to name their world for transformation purposes, they must be encouraged to participate in the formation and selection of the evaluative methods used to assess them. Thus, re-evaluating pedagogical aims and objectives, and creating alternative means to evaluate students' learning, are vital in critical pedagogy. As a result, teachers who are willing to employ critical pedagogy should tap into their own creativity to transform the means through which grades are determined and awarded, rather than relying on the same cynical and uninspiring methods used by so many in that profession (Forbes \& Kaufman, 2008).

The majority of the study participants believed that their mathematics education classroom did not accommodate engagement in practices or discussions which inspire both student teachers and educators to develop an understanding of the interconnecting relationship between mathematics, culture and society - rather, the focus was more on content. As one participant mentioned:

I do not see a connection between our mathematics classrooms and this type of pedagogy that you have just explained. Issues of racism, gender equality and other debates relating to societal unease and how to challenge them, are in no way accommodated in [the] mathematics method classroom, but we sometimes discuss them in other modules. Our mathematics method classroom focus[es] more on content to teach high school learners, nothing related to real-life situations and the things happening in the society. (ST7; University X)

From the above response, a case could be made that mathematics student teachers do not engage with their educators in social and critical discourse, as they do not see the link between mathematics and their immediate environment, most likely because their educators' pedagogical approaches focus mainly on content, rather than promoting problem-centred dialogue that originates from students' lived experiences. This finding concurs with the view of Kovalchuk (2015), who posits that a pedagogical approach which focuses mainly on transmissional and content-based training will only lead to the development of negligent citizens. Hence, the development of leading citizenship necessitates the use of collaborative, dynamic and critical pedagogies that can empower individuals to debate contested issues, exercise their rights through decision making and other activities, and enable them to think for themselves (Kovalchuk, 2015). As Bartolomé (1996, p. 249) posits, students will continue to struggle to master content that is unfamiliar to their reality, and opposes their culture and lived experiences, until the educational methods used in class are positioned within their cultural experiences. Mathematics teacher educators are strongly urged to create classrooms which incorporate diverse pedagogical approaches, to stimulate student engagement or promote epistemological interest in both parties, to ensure that democratically oriented skills and values are taught and learned.

The researchers also found that the vast majority of the participants did not see the need for such engagement in mathematics education classrooms, or identify the link between these pedagogical approaches, their mathematics classroom and their immediate society. As one mathematics educator stated:

I believe that mathematics help[s] us to develop analytical thinking which strengthens the ability to investigate and know the truth about the world around us, but [there is] no opportunity to engage with my students on issues that confront the society in [the] mathematic classroom because of several reasons, which include creating a link between mathematics and this teaching approach, time consumption, lesson plan preparation to accommodate such practices, extroverts hijacking such debates, accommodating other students who have different views and opinion[s] based on their background or race - such engagement might even lead to protest [s], or something. So, engaging in such [a] debate or discussion is literarily a waste of my time. (ME1; University Z)

As the participants' responses revealed, although they recognise the importance of mathematics, they do not see a link between a democratic pedagogical approach and what happens in mathematics classrooms, nor do mathematics educators believe in their ability to engage students in debates that might help them change their immediate society, by viewing social issues through a mathematical lens. Jansen $(2009$, p. 151) argues strongly that critical and social theories do not capacitate teachers to deal with the multifaceted challenges arising in post-conflict classrooms, only to pay lip service to the dialogic nature of education. In addition, the findings revealed that the nature of mathematics 
teaching, and the fear that learners come to class with different knowledges from their personal experience, and have disparate opinions, hinder critical and social engagement within mathematics education classrooms. This finding corroborates that of Jansen (2009), who states that learners do not have a single story from the past or a common understanding of the present or future goals that are similar - as a result, they come to class as bearers of diverse versions of received knowledge. Hence, teachers who fear the manifold experiences that learners bring to class, yet who wish to operate as promoters of social and critical theory, must cherish such variety amongst their learners after all, critical theory in its more radical form seeks to divide the world (Vandeyar \& Swart, 2016).

From the researchers' classroom observation, it was noticeable that the mathematics educators were trying to connect mathematical concepts to real-life issues in society. For instance, a mathematics educator at University Y attempted to link the calculation of volume, surface and total surface to real objects that were visible in the classroom and outside. That educator took it one step further and spoke about geometry in relation to how it is employed by architects in designing buildings. An explanation was given of the beauty of mathematics, in terms of how geometry informs the ways and patterns in which houses are constructed in different communities. Arguably, engagement in social and critical pedagogy goes beyond classroom explanation. It involves affording opportunities to students and learners to participate in dialogic discourse about the nature of the methods used, the essence of their schooling, and the role of mathematics in that process. Such a method of teaching would include the discovery and reading of research, participation in debates about teaching and curricula, and, most importantly, taking action to effect change within various sphere of influence (Freire, 1998; Roy \& Swaminathan, 2002; Ellis \& Malloy, 2007).

The institutional teaching and learning policy (university name not mentioned for review purposes) stipulates that an educator should adopt a humanising pedagogical approach which is based on care, trust and respect for and between educators and students, as both parties collectively and mutually engage in knowledge construction, meaningful learning and problem solving in a real-world context. Put differently, educators need to find ways to encourage students to bring what they know, who they are and what they want to be, into the mathematics classroom, in order to reach a conclusion on the cultural, social and political values that shape an entire being. In this way, mathematics student teachers will be able to achieve their fullest potential. The policy further states that educators must welcome scholarly debate, and encourage a critical exchange of ideas, views and experiences.

The research findings obtained from the interviews, in respect of how the participants engaged in critical and social pedagogy, corroborate the findings made during the classroom observation, but refute those obtained during the document review. The argument can thus be made, that what some participants earlier stated and believed to constitute critical and social engagement within the mathematics education classroom, lacked self-reflection because it failed to connect the development of individual, ethical responsibility to social change. Hence, such classroom practices or engagements are neither capable of moving both mathematics student teachers and their educators towards deeper understandings of their existing world (Greene, 1996), nor can they capacitate students with vital skills, character traits and knowledge to create a democratic community which seeks social justice and social change (Aslan-Tutak et al., 2011). As Mayo (2013) posits, engagement in social and critical pedagogy is about gaining an understanding of societal issues from culturally diverse perspectives, rather than mechanically receiving information. Thus, mathematics teachers who work in such spaces are encouraged to adopt these pedagogies to promote or drive transformation, through the expatiation of an imaginative appropriation of knowledge in the form of introspection and self-reliance, to critically shape the larger social order (Kincheloe, 2004). The attributes which teachers in such classrooms need, in order to facilitate effective learning, include meekness, lovingness, bravery, acceptance, determination, security, endurance and the joy of living (Freire, 1998).

\subsection{Reasons for Engaging in Critical and Social Pedagogy in the Mathematics Education Classroom}

The researcher took a step further, to establish the reason why participants would adopt such a pedagogical approach. The findings, which indicated that participants agreed they were involved in critical and social discourse in mathematics education classrooms, revealed that the majority did not see the need for such engagement as part of their formative experiences. As one participant stated:

Well, I do not see a need for such discussion in my method class, but I guess engaging in this type of debate will help me to develop better ways of socialising and be more exposed to different kinds of views from different people with different backgrounds and race[s] because learners' views are different, so all must be accommodated and respected. (ST2; University Z)

Another student teacher at a different institution commented: 
I engage with my lecturers on issues surrounding us in classrooms and the society, in order to develop a general knowledge and [the] skills required to solve [these] problems. But honestly, I don't think mathematics is useful in the society. So, I favour mathematics literacy in terms of applying what is learnt in the classroom to real-life situation[s]. (ST8; University Y)

The research findings revealed that participants who had claimed to engage, and explained how they engaged, in certain issues that challenged their immediate society through critical thinking, surprisingly did not see a need for such engagement in their mathematics classrooms. In this regard, Ernest (1994) states that students may not see the usefulness of mathematics in society, regardless of the teaching approaches employed, because their subject has been shaped to appear static and less clear within school curricula. Walshaw (2002) suggests that it is essential that mathematics student teachers be given opportunities to engage in serious critical discussions about teaching and curricula, which will provide them with opportunities to take action and influence (or even bring about) change within numerous spheres of power, including in their classrooms, the department, their school, their district, and so on. For Lilia (2004), promoting a teacher education classroom that has no hesitation in examining how ideologies function in relation to power, is the only practical way to ensure that student teachers develop political, social and ideological clarity. Lilia (2004) adds that it is imperative for would-be teachers to scrutinise political and cultural roles within the existing status quo, and then to transform those unsociable, destructive and fundamentally undemocratic principles and philosophies that inform autocratic practices within the education system. Hence, for the development of democratic citizens, it is also essential to understand pedagogical approaches in the teaching and learning space which can enhance the transmission of hidden messages, values and norms (Reyes, 2007).

One participant explained why he engages his students in critical and social discourse:

When we deal with equations in mathematics, the student has to compare the two sides. By solving for $x$ from an equation you have identified the aspect that will make the two sides equal. So, taking that concept of equation, you begin to relate it to societies in terms of access to schooling: what make[s] people not have access to schooling? The identification of this problem will then allow you to conscientise your mathematics students with respect and care, so that they can begin to see that mathematics is not a classroom activity, but rather it goes beyond the classroom space where it can directly confront social issues. (ME2; University Y)

The participant added:

... basically there are three signs which are commonly used in mathematics contents which are the 'equal' sign, 'greater than', and the 'smaller than' sign. The application of [these] signs goes beyond the classroom, because it relates to the society. These signs inform the issue of equity, access, participation by all, which are critical element[s] for the realisation of social justice. So, mathematics itself promotes the aspect of social justice when it is well interpreted by the one who is delivering the content in class. (ME2; University Y)

The above interesting view on why the mathematics educator engaged his students in social and critical dialogue, reveals that such engagement is capable of empowering student teachers with the understanding, abilities and character needed to build democratic communities which embrace social justice in schools, and in society at large. Stinson et al. (2012) posit that in order to normalise teachers into becoming critical mathematics educators, mathematics teacher education programmes must embrace the teaching of mathematics for social justice through social and critical pedagogy. As such, pedagogues need to recognise that students are immersed in a complex relational system of support (Cameron et al., 2011); they should also organise classroom discourse in a way that exemplifies the practice of engaging students or learners in the social conception of knowledge, which establishes its pillars on power relations (Sarroub \& Quadros, 2015). Aslan-Tutak et al. (2011) add that critical pedagogy in mathematics education has the potential to cultivate citizens who are socially just, and to advance a democratic society. Succeeding academically in the typical sense, changing learners'/students' and teachers'/educators' conception of mathematics, and reading the mathematical word (literacy) and world simultaneously, are the main goals of mathematical pedagogy (Gutstein, 2006). Thus, reading in this context implies developing mathematical powers such as understanding mathematical simplification, the construction of creative solutions for non-routine problems, and recognising mathematics as a tool for socio-political criticism (Gutstein, 2003). To develop lifelong learners who are capable of participating in an evolving social and critical pedagogy, teachers and school administrators should strive to develop critical learning experiences that blend the standardised curriculum with learners' actual lives (Gutstein, 2006). 
A striking finding here is that mathematics educators and HEI authorities reject social and critical dialogue within the classroom and the university at large, in order to stay within their "institutional box" and avoid institutional vulnerability.

\section{Conclusion}

Engagement in social and critical pedagogy is capable of empowering students to develop their mathematical abilities and their position of power, and to change their orientation toward the subject. The research findings revealed that mathematics teacher education classrooms do not embrace social and critical pedagogy. In fact, educators still cling to traditional pedagogical approaches, and show almost complete ignorance of the philosophy and utility of social and critical pedagogy. Similarly, the classroom setup, and traditional grading and assessment techniques employed in the mathematics education classrooms under study, presented obstacles which hinder that type of engagement. Hence, apart from the problem being created by the tendency to implement centrally controlled examinations, educators are always challenged with inconsistencies in the curricula, which are drawn up in the spirit of critical literacy, as are the supplementary educational materials and implementation guidelines for educators.

\section{Recommendations}

Based on the findings of the study, it is recommended that the role of teachers who engage learners in social and critical pedagogy in the mathematics education classroom should go beyond dialogue based on a foundation of conceptual understanding. That approach compels learners to submit the "right" answers, instead of stimulating engagement through questions which do not impose views and opinions on learners. In addition, mathematics teacher educators must employ a problem-posing pedagogical approach which is capable of challenging power structures, thereby embracing and empowering students to truly use mathematics. The proposed pedagogy can provide learners with a better understanding of social issues, as it stems from multicultural and diverse perspectives. Such a pedagogical approach also expands the imagination and allows the appropriation of knowledge in the form of self-reflection, a synergy of care, and self-determination which seeks to foster democratic values and critical consciousness in the development of democratic citizens.

\section{References}

Agyemang, B. (2012). Democratic education for social improvement: An exploration of the views of pupils and teacher trainees in Ghana [Unpublished $\mathrm{PhD}$ thesis]. University of Birmingham.

Aslan-Tutak, F., Bondy, E., \& Adams, T. (2011). Critical pedagogy for critical mathematics education. International Journal of Mathematical Education in Science and Technology, 42(1), 65-74. https://doi.org/10.1080/0020739X.2010.510221

Bartolomé, L. I. (1996). Beyond the methods fetish: Toward a humanizing pedagogy. In P. Leistyna \& S. A. Woodrum (Eds.), Breaking free: The transformative power of critical pedagogy (pp. 229-252). Harvard University Press.

Bickel, C. (2006). Cultivating orchids: Promoting democracy in the classroom. In P. Kaufman, \& P. Kaufman (Eds.), Critical pedagogy in the classroom (pp. 93-107). American Sociological Association.

Black, E., Bettencourt, M., \& Cameron, C. (2017). Social pedagogy in the classroom: Supporting children and young people in care. In D. Colley, \& P. Cooper (Eds.), Attachment and emotional development in the classroom: Theory and practice. Jessica Kingsley.

Bloom, B. S. (1956). Taxonomy of educational objectives: The classification of educational goals. Handbook I: Cognitive Domain. McKay.

Braun, V., \& Clarke, V. (2006). Using thematic analysis in psychology. Qualitative research in psychology, 3(2), 77-101. https://doi.org/10.1191/1478088706qp063oa

Cameron, C., Petrie, P., Wigfall, V., Kleipoedszus, S., \& Jasper, A. (2011). Final report of the social pedagogy pilot programme: Development and implementation. Institute of Education, University of London, Thomas Coram Research Unit.

Cotton, T. (2013). Critical mathematics education: From theory to practice. In A. B. Coles (Ed.), Teaching secondary mathematics as if the planet matters (pp. 87-97). Routledge.

Darling-Hammond, L. (2010). Teacher education and the American future. Journal of Teacher Education, 61(1/2), 35-47. https://doi.org/10.1177/0022487109348024 
Eichsteller, G., \& Holthoff, S. (2012). The art of being a social pedagogue: Developing cultural change in children's homes in Essex. International Journal of Social Pedagogy, 1(1), 30-46. https://doi.org/10.14324/111.444.ijsp.2012.v1.1.004

Ellis, M., \& Malloy, C. E. (2007). Preparing teachers for democratic mathematics education. In D. Pugalee (Ed.), Proceedings of the Ninth International Conference on Mathematics Education in a Global Community (pp. 160-164). https://www.academia.edu/1352569/Proceedings_of_the_Ninth_International_Conference_-Mathematics_Educ ation_in_a_Global_Community

Ernest, P. (1994). Constructing mathematical knowledge: Epistemology and mathematical education. Falmer Press.

Fang, Z. (2012). Approaches to developing content area literacies. Journal of Adolescent \& Adult Literacy, 56(2), 103-107. https://doi.org/10.1002/JAAL.00110

Forbes, C., \& Kaufman, P. (2008). Critical pedagogy in the sociology classroom: Challenges and concerns. Teaching Sociology, 36(1), 26-33. https://doi.org/10.1177/0092055X0803600104

Franzosi, R. (2006). Pedagogical philosophy. In P. Kaufman (Ed.), Critical pedagogy in the classroom (pp. 14-19). American Sociological Association.

Freire, P. (1968). Pedagogy of the oppressed. Continuum.

Freire, P. (1970). Pedagogy of the oppressed (M. B. Ramos, Trans.) Continuum.

Freire, P. (1998). Pedagogy of freedom: Ethics, democracy and civic courage. Rowman and Littlefield.

Giroux, H. A. (2006). Academic freedom under fire: The case for critical pedagogy. College Literature, 1-42. https://doi.org/10.1353/lit.2006.0051

Giroux, H. A. (2010). Rethinking education as the practice of freedom: Paulo Freire and the promise of critical pedagogy. Policy Futures in Education, 8(6), 715-721. https://doi.org/10.2304/pfie.2010.8.6.715

Greene, M. (1996). In search of a critical pedagogy. In P. Leistyna, \& S. A. Woodrum (Eds.), Breaking free: The transformative power of critical pedagogy (pp. 13-30). Harvard University Press.

Groth, R. (2006). Expending teachers' understanding of geometric definition: The case of trapezoid. Teaching Children Mathematics, 12(7), 376-380. https://doi.org/10.5951/TCM.12.7.0376

Gutstein, E. (2003). Teaching and learning mathematics for social justice in an urban, Latino school. Journal for Research in Mathematics Education, 34(1), 37-73. https://doi.org/10.2307/30034699

Gutstein, E. (2006). Reading and writing the world with mathematics: Toward a pedagogy for social justice. Routledge.

Gutstein, E., \& Peterson, B. (2005). Rethinking mathematics: Teaching social justice by the numbers. Rethinking Schools.

Harber, C. (1997). Education, democracy and political development in Africa. Sussex Academic Press.

Harber, C. (2009). Toxic schooling: How schools became worse. Educational Heretics Press.

Harper, F. (2018). Solving world problems: Equity \& social justice in mathematics education. https://francesharper.com/social-justice-math/

Jansen, J. (2009). On the clash of martyrological memories. Perspectives in Education, 27(2), 147-157.

Kincheloe, J. L. (2004). The knowledge of teacher education: Developing a critical complex epistemology. Teacher Education Quarterly, 31(1), 49-66.

Kovalchuk, S. (2015). Teacher education for democracy in post-Soviet Ukraine [Unpublished $\mathrm{PhD}$ thesis]. University of Toronto.

Lilia, I. (2004). Critical pedagogy and teacher education: Radicalizing prospective teachers. Teacher Education Quarterly, 31(1), 97-122.

Lloyd, J., Larkins, C., Charfe, L., Moorcroft, A., \& Bramwell, S. (2014). Social pedagogy approach to learning improves direct work with children. https://www.communitycare.co.uk/2014/11/06/social-pedagogy-brings-social-work-students-young-people-care -workers-together-learn/ 
Mayo, C. (2013). Queer lessons: Sexual and gender minorities in multicultural education. In J. A. Banks, \& C. A. Banks (Eds.), Multicultural education: Issues and perspectives (pp. 209-228). John Wiley \& Sons.

McKinney, K., Howery, C. B., Strand, K. J., \& Kain, E. L. (2004). Liberal learning and the Sociology major updated. American Sociological Association.

McLaren, P. (2009). Critical pedagogy: A look at major concepts. In D. Baltodano, \& R. Torres (Eds.), Critical theory and methodology (pp. 61-83). Routledge.

Ormston, R., Spencer, L., Barnard, M., \& Snape, D. (2014). The foundations of qualitative research. Qualitative research practice: A guide for social science students and researchers, 2(1), 52-55.

Patel, R. (2010). The banking concept of education vs. problem posing. https://www.bartleby.com/essay/The-Banking-Concept-of-Education-vs-Problem-PKKPXNL36ZYA

Petrie, P. B., Heptinstall, E., McQuail, S., Simon, A., \& Wigfall, V. (2009). Pedagogy - a holistic, personal approach to work with children and young people, across services: European models for practice, training, education and qualification. Thomas Coram Research Unit.

Reyes, R. (2007). Marginalized students in secondary school settings: The pedagogical and theoretical implications of addressing the needs of student sub-populations. Journal of Border Educational Research, 6(2), 3-5.

Roy, K., \& Swaminathan, R. (2002). School relations: Moving from monologue to dialogue. High School Journal, 85(4), 40-51. https://doi.org/10.1353/hsj.2002.0012

Sarroub, L., \& Quadros, S. (2015). Critical pedagogy in classroom discourse. In M. Bigelow, \& J. Ennser-Kananen (Eds.), Critical pedagogy in classroom discourse (pp. 252-260). Routledge.

Skovsmose, O. (2011). Critique, generativity and imagination. For the Learning of Mathematics, 31(3), 19-23.

Soertard, M. (1994). Johann Heinrich Pestalozzi. Prospects - Quarterly Review of Education (Thinkers on Education), 24(1/2), 297-310. https://doi.org/10.1007/BF02199022

Stemhagen, K., \& Smith, J. (2008). Dewey, democracy and mathematics education: Reconceptualizing the last bastion of curricular certainty. Journal of Education and Culture, 24(2), 25-40. https://doi.org/10.1353/eac.0.0023

Stinson, D. W., Wager, A., \& Leonard, J. (2012). Teaching mathematics for social justice: Conversations with educators. Reston, VA: National Council of Teachers of Mathematics.

Trent, A., Cho, J., Rios, F., \& Mayfield, K. (2010). Democracy in education: Learning from preservice teachers' understanding and perspectives. Journal of the NNER, 2(1), 183-210.

Turner, E. E., \& Font Strawhun, B. T. (2007). Posing problems that matter: Investigating school overcrowding. Teaching Children Mathematics, 13(9), 457-463. https://doi.org/10.5951/TCM.13.9.0457

Vandeyar, S., \& Swart, R. (2016). Educational change: A case for pedagogy of compassion. Education as Change, 20(3), 141-159. https://doi.org/10.17159/1947-9417/2016/1362

Walshaw, M. (2002). Epistemic terrains and epistemic responsibility. Philosophy of Mathematics Education Journal, 16(1), 1-6.

Wonnacott, V. (2011). Teaching Mathematics for Social Justice and its Effects on Affluent Students. University of Toronto: Unpublished M.Ed. Thesis of Graduate Department of Curriculum, Teaching and Learning.

Wright, P. (2016). Social justice in the mathematics classroom. London Review of Education, 14(2), 104-118. https://doi.org/10.18546/LRE.14.2.07

Yin, R. K. (2013). Validity and generalization in future case study evaluations. Evaluation, 19(3), 321-332. https://doi.org/10.1177/1356389013497081

\section{Copyrights}

Copyright for this article is retained by the author(s), with first publication rights granted to the journal.

This is an open-access article distributed under the terms and conditions of the Creative Commons Attribution license (http://creativecommons.org/licenses/by/4.0/). 